\title{
Investigation on the Growth, Structural and Third Order Nonlinear Optical Properties of 4- Ethoxy-4'-N'-Methyl-4-Stilbazoliumhexafluorophosphate (EMSHP) Single Crystal
}

\author{
A. Karolin Martina, J. Reena Priya, N.S. Nirmala Jothi*, P. Sagayaraj \\ Department of Physics, Loyola College, Chennai - 600 034, Tamilnadu, India.
}

\section{ART ICLE DETAILS}

\section{Article history:}

Received 17 April 2018

Accepted 26 April 2018

Available online 23 May 2018

\section{Keywords:}

Organic Compounds

Crystal Structure

Nonlinear Optical Materials

Nonlinear Refractive Index

Terahertz Technology

\begin{abstract}
A B S T R A C T
The organic material 4-ethoxy-4'-N'-methyl-4-stilbazolium hexafluorophosphate (EMSHP) is a new NLO material and new derivative in stilbazolium tosylate family. In this work we synthesized EMSHP, the derivative of DAST, by slow evaporation method. The chromophores of the EMSHP crystal makes an angle of about 28 with repeat to a- axis which makes this material a promising terahertz (THz) wave generation and used for various electro - optic applications. The crystal system is found as monoclinic. From the UV-Vis NIR absorption spectra the good transparency is revealed. The indication at $498 \mathrm{~nm}$ of the crystal ascertains the blue to green emission was validated by using photo luminescence (PL) analysis. The third-order nonlinear optical properties such as nonlinear refractive index $\left(\mathrm{n}^{2}\right)$, absorption co-efficient $(\beta)$ and susceptibility $\left(\chi^{(3)}\right)$ were studied by Z-scan technique at $632.8 \mathrm{~nm}$ using He-Ne laser. All the above studies supports the as grown EMSHP crystal is a suitable candidate for generation of $\mathrm{THz}$ and opto- electronic application.
\end{abstract}

\section{Introduction}

Nonlinear optical materials in the recent years have been intensively studied for different design, NLO efficiency which has attracted the fields of applications in opto electronic and THz generation devices [1-3]. The field of electronics and photonics has reached a new family of materials as a result of poly conjugated push- pull organic chromophores. The nonlinear optical response and the $\pi$ - system relation like donor to acceptor is needed discussion for charge transfer (CT). This platform has used too many experimental and theoretical investigations [4-9]. A $\pi$ conjugated space enables electron donor (D) and electron accepter (A) interactions assisted with large second order polarizabilites, high NLO response all the basis of dipolar push-pull organic NLO family crystals [10, 11]. The NLO efficiency is validated by the hyperpolarizability value ( $\beta$ ) and substantiated by the donor - acceptor pair (DAP) strength. Aromatic units builds up the $\pi$-conjugated path and spacers, where the aromatic systems is made by the response stillbazolium energy. The knowledge of NLO properties at the molecule level, helps in the optimization of materials for new NLO devices. Many families of their properties can be compared with the in-depth understanding of the intrinsic molecular hyperpolarizability values of $\beta$ and $\gamma[12,13]$. The crystallization in a centrosymmetric space group is the characteristics of dipolar molecules which possess high polarizability value. Crystal with maximum efficiency with phase matching conditions can be obtained when the NLO chromophores are packed in the ideal orientation [14]. Nonlinear second order crystals can be formed by crystallizing cations chromophores with large $\beta$ and anions. The group of $\chi^{(2)}$ active crystalize 4-N-methyl stillbazolium crystal families by knowing the salt methodology. The bulk form of 4-( $N, N$-dimethylamino)- $N$-methyl- 4- toluene sulfonate (DAST) has pronounced quadratic NLO activity and powder form of DAST has SHG efficiency of ca 1000 times as that of urea in laser emission of $1907 \mathrm{~nm}$. If the molecule aligned in the same direction in a crystal than large nonlinear coefficients can be obtained, used in opto -electronic application [15]. The electro-optic coefficient $\left(\mathrm{r}_{11}\right)$ in $160 \pm 50 \mathrm{pm} / \mathrm{V}$, static first hyperpolarizability $\left(\beta_{0}\right)$ is $364 \times 10^{-30}$ esu was found by Rayleigh scattering. DAST crystals have high band width of $140 \mathrm{GHz}$ and large second order NLO coefficients $d_{11}=1010 \pm 110 \mathrm{pm} / \mathrm{V}$ at $1318 \mathrm{~nm}$ makes this materials a promising for ultrafast electro-optical modulation $[16,17]$. The electron

\section{Experimental Methods}

\subsection{Synthesis}

EMSHP was synthesized by metathesization of the 4ethoxybenzaldehyde-N-dmethyl-4-stilbazolium iodide (EMSI) salt with sodium hexafluorophosphate. EMSI was synthesized by the condensation of 1,4- dimethyl pyridinium iodide $(2.35 \mathrm{~g}, 10 \mathrm{mmol})$, methanol $(30 \mathrm{~mL})$ and 4-ethoxy benzaldehyde $(1.36 \mathrm{~g}, 10 \mathrm{mmol})$ in the presence of piperidine $(0.2 \mathrm{~mL})$. The total mixture was taken in a round-bottom flask (1000 mL capacity) of a Dean- Stark apparatus and refluxed for 15 hours, then cooled to room temperature. The product was filtered and recrystallized from methanol four times for purification. During the next stage, the metathesization reaction was carried out with aqueous sodium hexafluorophosphate. A yellowish precipitate was formed as a result of exchange reaction between anion and cation. The remaining aqueous sodium iodide solution was removed from the precipitation. The purity of EMSHP was further improved by successive recrystallization from acetone. This synthesis scheme is depicted on Fig. 1. 


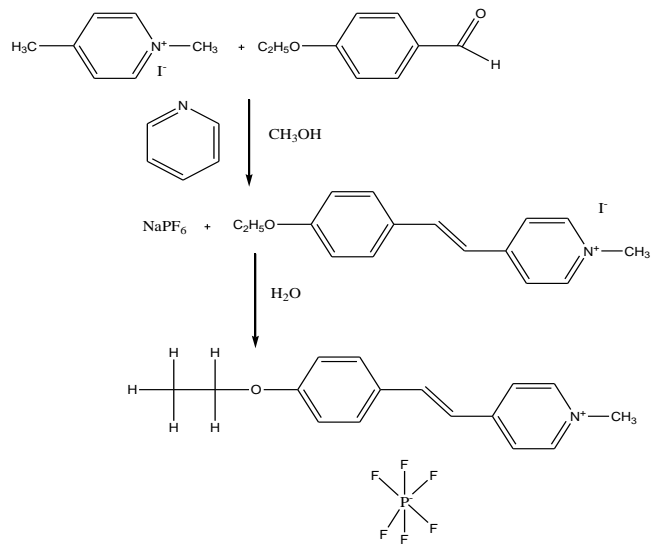

Fig. 1 Synthesis scheme of EMSHP

\subsection{Crystal Growth}

After testing several common solvents and their combinations, it was found that the solubility of EMSHP can be improved by using acetone. The size of the grown crystals were small when acetone was used as solvent. The size of the grown crystals improved a lot when the mixed solvent of water and acetone was used as solvent. We compared solvent mixtures of acetone and water with 5:1, 4:1,3:1,2:1 and 1:1 proportion and found that EMSHP dissolved best and the size of the crystals were bigger for the 3:1 ratio. $100 \mathrm{~mL}$ of the above mentioned solvent was taken in a beaker and $1.7 \mathrm{~g}$ of EMSHP was added slowly and stirred continuously for three days to prepare a saturated solution at room temperature. The saturated solution was filtered, sealed with perforations and was set aside to undergo slow evaporation. The solubility curve is show in Fig. 2. After two weeks, crystals of size up to $7 \mathrm{~mm} \times 1 \mathrm{~mm} \times 1 \mathrm{~mm}$ were obtained. The photograph of as-grown crystal is shown in Fig. 3.

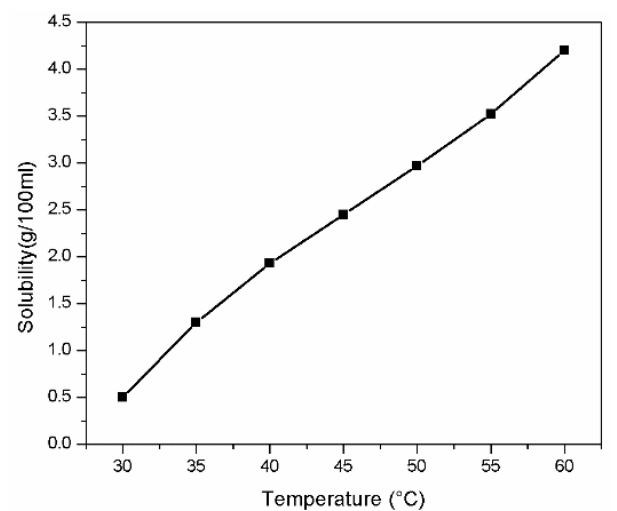

Fig. 2 Solubility curve for EMSHP

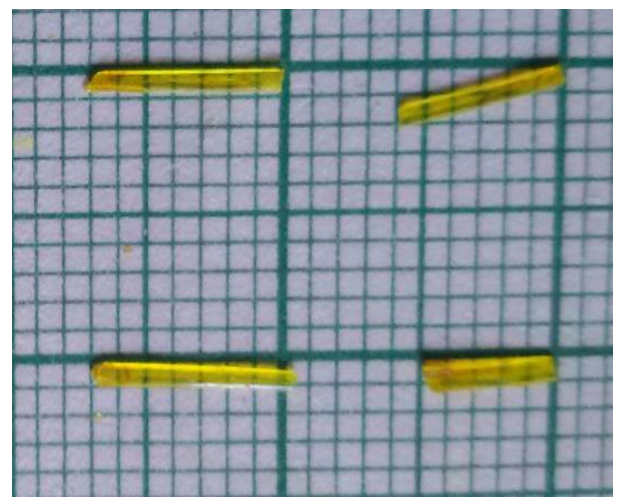

Fig. 3 Photograph of EMSHP crystals

\section{Results and Discussion}

\subsection{Single Crystal XRD}

Single crystal XRD data were collected using an automated diffractometer (Bruker Axs Kappa APEX 11) with MoKa radiation of wavelength $0.07170 \AA$ at $293 \mathrm{~K}$. SHELXL programme was used for structure solving and refinement. The structure was solved by direct methods and full-matrix least squares refinement $\mathrm{F}^{2}$ taking all the unique reflection. The obtained data for EMSHP along with experiment conditions https://doi.org/10.30799/jnst.114.18040307 and structure refine parameters are listed in Table 1 . The hydrogen atoms causing the $\mathrm{H}$-bonds were located from the different Fourier and refined with isotropic thermal parameters while the non-hydrogen atoms were refined with anisotropic thermal parameters. From Table 1 that the EMSHP crystal belong to monoclinic system with space group $\mathrm{P} 2{ }_{1}$, which comes from under non-centrosymmetric crystal structure. The atomic coordinates and equivalent isotropic displacement parameters, anisotropic displacement parameters, the hydrogen co-ordinates and isotropic displacement parameters and the torsion angle of EMSHP are listed in Table 2 respectively.

The ORTEP representation of one ion-pair of EMSHP is shown in Fig. 4. The packing diagram of EMSHP indicates that the planer stilbazolium chromophores are aligned perfectly parallel with the head-to-head arrangements of the near stilbazolium portions of the cation. This favourable orientation adds up the microscopic polarization into macroscopic effect, thereby increasing nonlinear coefficient Fig. 5 shows that the unit cell of EMSHP with two ion pars per unit cell, and the $\mathrm{PF}_{6}$ anion are located close to the electron deficient pyridium ring of the cations.

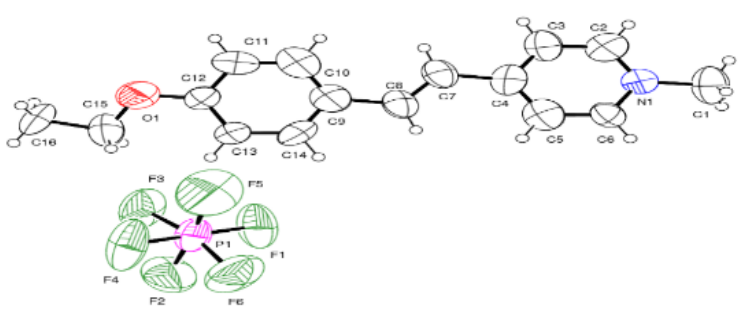

Fig. 4 ORTEP diagram of EMSHP crystal

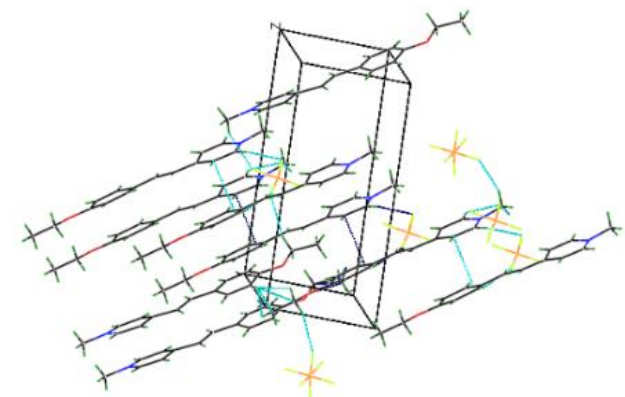

Fig. 5 The crystal packing along $c$ direction, showing $10 \%$

Table 1 Crystal data and structure refinement for EMSHP

\begin{tabular}{|c|c|}
\hline Parameter & Value \\
\hline Identification code & EMSHP \\
\hline Empirical formula & $\mathrm{C}_{16} \mathrm{H}_{18} \mathrm{~F}_{6} \mathrm{NOP}$ \\
\hline Formula weight & 385.28 \\
\hline Temperature & $293(2) \mathrm{K}$ \\
\hline Wavelength & $0.71073 \AA$ \\
\hline Crystal system & Monoclinic \\
\hline Space group & $\mathrm{P} 2_{1}$ \\
\hline Unit cell dimensions & $\begin{array}{ll}a=6.4011(14) \AA & \alpha=90^{\circ} . \\
b=9.498(2) \AA & \beta=94.568(4)^{\circ} . \\
c=14.360(3) \AA & \gamma=90^{\circ} .\end{array}$ \\
\hline Volume & $870.3(4) \AA^{3}$ \\
\hline $\mathrm{Z}$ & 2 \\
\hline Density (calculated) & $1.470 \mathrm{mg} / \mathrm{m}^{3}$ \\
\hline Absorption coefficient & $0.222 \mathrm{~mm}^{-1}$ \\
\hline $\mathrm{F}(000)$ & 396 \\
\hline Crystal size & $0.250 \times 0.200 \times 0.200 \mathrm{~mm}^{3}$ \\
\hline Theta range for data collection & 2.573 to $24.996^{\circ}$. \\
\hline Index ranges & $-7<=\mathrm{h}<=7,-11<=\mathrm{k}<=11,-17<=\mathrm{l}<=17$ \\
\hline Reflections collected & 9145 \\
\hline Independent reflections & 9145 [R(int) = ?] \\
\hline Completeness to theta $=24.996^{\circ}$ & $99.1 \%$ \\
\hline Absorption correction & Semi-empirical from equivalents \\
\hline Max. and min. Transmission & 0.7457 and 0.6525 \\
\hline Refinement method & Full-matrix least-squares on $\mathrm{F}^{2}$ \\
\hline Data / restraints / parameters & 9145 / $400 / 454$ \\
\hline Goodness-of-fit on $\mathrm{F}^{2}$ & 1.036 \\
\hline Final $R$ indices [I>2sigma(I)] & $\mathrm{R} 1=0.0427, \mathrm{wR} 2=0.0930$ \\
\hline $\mathrm{R}$ indices (all data) & $\mathrm{R} 1=0.0753, \mathrm{wR} 2=0.1112$ \\
\hline Absolute structure parameter & $0.30(8)$ \\
\hline Extinction coefficient & $\mathrm{n} / \mathrm{a}$ \\
\hline Largest diff. peak and hole & 0.152 and -0.107 e. $\AA^{-3}$ \\
\hline
\end{tabular}


Table 2 Atomic coordinates $\left(\times 10^{4}\right)$ and equivalent isotropic displacement parameters $\left(\AA^{2} \times 10^{3}\right)$ for EMSHP. U(eq) is defined as one third of the trace of the orthogonalized Uij tensor

\begin{tabular}{|c|c|c|c|c|}
\hline & $X$ & $\mathrm{Y}$ & $\mathrm{z}$ & $\mathrm{U}(\mathrm{eq})$ \\
\hline$\overline{\mathrm{C}(1)}$ & $22240(30)$ & $-430(30)$ & $4628(16)$ & $124(7)$ \\
\hline $\mathrm{N}(1)$ & $20330(30)$ & $-60(30)$ & $4012(16)$ & $75(5)$ \\
\hline $\mathrm{C}(2)$ & $19660(50)$ & $1250(30)$ & $3770(20)$ & $99(10)$ \\
\hline $\mathrm{C}(3)$ & $17800(50)$ & $1490(30)$ & $3280(30)$ & $100(10)$ \\
\hline $\mathrm{C}(4)$ & $16570(50)$ & $390(50)$ & $2940(30)$ & $90(10)$ \\
\hline $\mathrm{C}(5)$ & $17230(40)$ & $-970(40)$ & $3230(30)$ & $106(10)$ \\
\hline$C(6)$ & $19090(50)$ & $-1160(30)$ & $3750(30)$ & $95(9)$ \\
\hline $\mathrm{C}(7)$ & $14540(50)$ & $790(30)$ & $2424(18)$ & $92(7)$ \\
\hline$C(8)$ & $13270(50)$ & $-140(40)$ & $2006(17)$ & $93(7)$ \\
\hline$C(9)$ & $11280(50)$ & $280(40)$ & $1440(20)$ & $101(10)$ \\
\hline$C(10)$ & $10430(60)$ & $1600(30)$ & $1340(20)$ & $110(11)$ \\
\hline $\mathrm{C}(11)$ & $8650(50)$ & $1790(20)$ & $790(20)$ & $111(10)$ \\
\hline$C(12)$ & $7610(40)$ & $690(30)$ & $336(19)$ & $80(7)$ \\
\hline $\mathrm{C}(13)$ & $8330(40)$ & $-640(30)$ & $514(19)$ & $88(9)$ \\
\hline$C(14)$ & $10160(50)$ & $-830(30)$ & $1080(30)$ & $98(10)$ \\
\hline$O(1)$ & $5730(30)$ & $985(18)$ & $-176(13)$ & $120(6)$ \\
\hline$C(15)$ & $4840(40)$ & $-100(40)$ & $-710(20)$ & $118(11)$ \\
\hline$C(16)$ & $2830(30)$ & $490(30)$ & $-1226(14)$ & 102(8) \\
\hline $\mathrm{F}(1)$ & $5266(19)$ & $-4570(20)$ & $3398(7)$ & $142(7)$ \\
\hline $\mathrm{F}(2)$ & $2670(40)$ & $-5860(30)$ & $2710(20)$ & $167(9)$ \\
\hline $\mathrm{F}(3)$ & $2170(40)$ & $-3750(20)$ & $2715(16)$ & 153(8) \\
\hline $\mathrm{F}(4)$ & $520(12)$ & $-5070(30)$ & $3648(10)$ & $169(8)$ \\
\hline$F(5)$ & 2830 & $-3700(30)$ & $4313(17)$ & $206(14)$ \\
\hline $\mathrm{F}(6)$ & $3350(30)$ & $-6175(16)$ & $4130(16)$ & 171(8) \\
\hline $\mathrm{P}(1)$ & $2880(20)$ & $-4810(18)$ & $3516(10)$ & $85(5)$ \\
\hline $\mathrm{C}\left(1^{\prime}\right)$ & $22370(50)$ & $640(40)$ & $4549(19)$ & $103(10)$ \\
\hline $\mathrm{N}\left(1^{\prime}\right)$ & $20310(40)$ & $690(40)$ & $4010(20)$ & $62(6)$ \\
\hline$C\left(2^{\prime}\right)$ & $19000(60)$ & $1730(30)$ & $3710(30)$ & $78(10)$ \\
\hline $\mathrm{C}\left(3^{\prime}\right)$ & $17120(70)$ & $1420(50)$ & $3250(40)$ & $82(12)$ \\
\hline$C\left(4^{\prime}\right)$ & $16570(80)$ & $90(50)$ & $3000(40)$ & $73(12)$ \\
\hline$C\left(5^{\prime}\right)$ & $18020(70)$ & $-960(40)$ & $3230(30)$ & $79(10)$ \\
\hline$C\left(6^{\prime}\right)$ & $19720(60)$ & $-680(40)$ & $3850(30)$ & $71(10)$ \\
\hline $\mathrm{C}\left(7^{\prime}\right)$ & $14720(60)$ & $-280(40)$ & $2420(20)$ & $70(8)$ \\
\hline $\mathrm{C}\left(8^{\prime}\right)$ & $13350(70)$ & $630(30)$ & $2060(20)$ & $61(9)$ \\
\hline$C\left(9^{\prime}\right)$ & $11390(50)$ & $200(40)$ & $1494(19)$ & $53(9)$ \\
\hline$C\left(10^{\prime}\right)$ & $10350(60)$ & $1340(30)$ & $1070(30)$ & $64(9)$ \\
\hline $\mathrm{C}\left(11^{\prime}\right)$ & $8370(50)$ & $1160(30)$ & $560(20)$ & $60(9)$ \\
\hline $\mathrm{C}\left(12^{\prime}\right)$ & $7610(40)$ & $-190(30)$ & $381(18)$ & $49(7)$ \\
\hline$C\left(13^{\prime}\right)$ & $8750(60)$ & $-1350(30)$ & $770(20)$ & $77(9)$ \\
\hline$C\left(14^{\prime}\right)$ & $10640(70)$ & $-1110(30)$ & $1300(30)$ & $71(9)$ \\
\hline$O\left(1^{\prime}\right)$ & $5880(30)$ & $-547(17)$ & $-150(11)$ & $59(5)$ \\
\hline$C\left(15^{\prime}\right)$ & $4670(60)$ & $470(40)$ & $-610(30)$ & $83(11)$ \\
\hline$C\left(16^{\prime}\right)$ & $2880(50)$ & $-280(30)$ & $-1210(20)$ & $98(10)$ \\
\hline$F\left(1^{\prime}\right)$ & $4740(30)$ & $-5320(30)$ & $3420(20)$ & $215(14)$ \\
\hline $\mathrm{F}\left(2^{\prime}\right)$ & $1840(70)$ & $-5880(30)$ & $2830(20)$ & $200(20)$ \\
\hline $\mathrm{F}\left(3^{\prime}\right)$ & $3260(70)$ & $-3560(30)$ & $2790(30)$ & $240(20)$ \\
\hline $\mathrm{F}\left(4^{\prime}\right)$ & $550(40)$ & $-4050(30)$ & $3530(20)$ & $223(14)$ \\
\hline$F\left(5^{\prime}\right)$ & $3600(50)$ & $-3760(50)$ & $4240(30)$ & 194(17) \\
\hline$F\left(6^{\prime}\right)$ & $2600(50)$ & $-5510(30)$ & $4355(17)$ & $186(15)$ \\
\hline $\mathrm{P}\left(1^{\prime}\right)$ & $2640(40)$ & $-4690(20)$ & $3459(16)$ & $87(8)$ \\
\hline
\end{tabular}

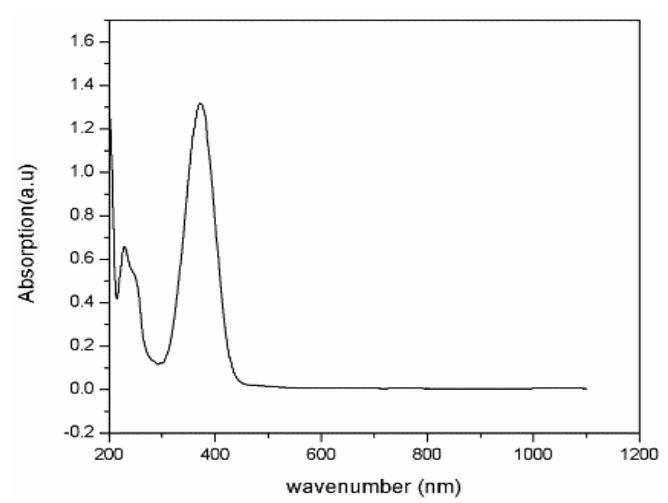

Fig. 6 Optical absorbtion spectrum of EMSHP crystal

\subsection{Optical Transmittance Studies}

The optical transmittance range and the transparency cut off wavelength of single crystal are most significant optical parameters for laser frequency applications. The optical absorption spectrum of EMSHP crystal in solution form was recorded in the wavelength range of 200 -
$1100 \mathrm{~nm}$ using Varian Cary 5E UV-VIS-NIR spectrometer using acetone and water as solvent show in Fig. 6. Absorbance is not found in the wavelength region of $445-1100 \mathrm{~nm}$ and it shows an excellent optical behavior of the crystal. The spectrum gives two prominent peaks, one intense peak at $377 \mathrm{~nm}$ corresponds to $\pi-\pi^{*}$ transition, and another at $227 \mathrm{~nm}$ corresponds to $\mathrm{n}-\pi^{*}$ transition. It is also reported that absence of absorption in the region between 445 and $1100 \mathrm{~nm}$ showed that EMSHP crystal could be exploited for second and third order nonlinear optical applications using Nd:YAG laser [22].

\subsection{Photo Luminance}

Fig. 7 depicts the photo luminescence spectra of the EMSHP crystal. It was carried out for a range of 400-900 $\mathrm{nm}$. The excitation wavelength of $400 \mathrm{~nm}$ was implemented for the PL spectrum. The blue to green emission corresponding to broad peak observed at $498 \mathrm{~nm}$ which can be used as potential blue-to-green phosphors in near-UV LED driven wLEDs. The peak intensity and the sharpness seen in the spectrum tells that the EMSHP crystal is highly crystalline in nature. The emission band as seen in the spectrum of EMSHP single crystals is broadened and this is due to intermolecular interactions of the EMSHP single crystal.

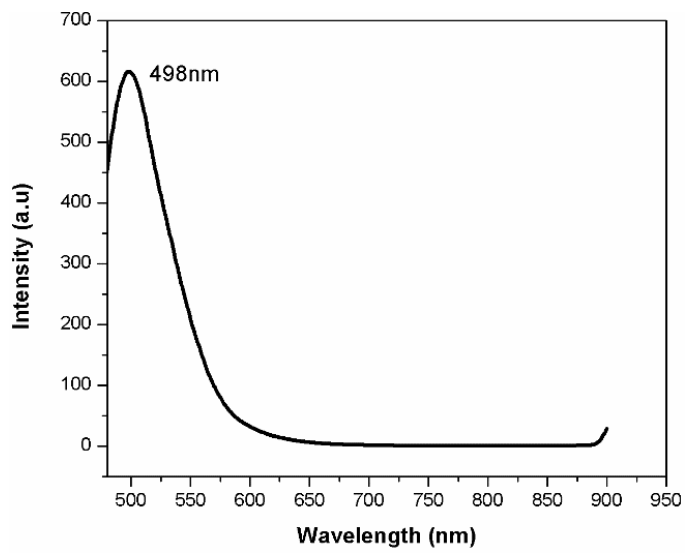

Fig. 7 Photo luminescence HMSCB single crystals

\subsection{Nonlinear Optical Properties by Z - Scan Study}

The optical nonlinearities of instrumental atoms is forasmuch as of high level of electron delocalization and it is the primary distribute of the perceptible or IR range [23]. The third-order NLO properties of EMSHP were scrutinized utilizing Z-scrutinize order to make up one's inclination the third supplication nonlinear refractive index $\left(\mathrm{n}^{2}\right)$ and nonlinear absorption co-efficient $(\beta)[24,25]$ utilizing He-Ne optical maser $(5 \mathrm{~mW})$ of wavelength at $632.8 \mathrm{~nm}$ was utilized as a spring and the well coldness across is $0.5 \mathrm{~mm}$. The optical maser column was engaged with Gaussian channel to innovate over info laser shaft into Gaussian plan. The captive Gaussian day issue TEM00 was exercised by a fraudulent focal individuality $(30 \mathrm{~mm})$ to begotten assert midriff $\omega \mathrm{o}=12.05 \mu \mathrm{m}$. The thickness of the example (L) is $1 \mathrm{~mm}$. The Rayleigh coil (ZR) was figurative to be $0.7207 \mathrm{~mm}$ utilizing the equality). The Rayleigh length constituent $(Z R>L)$ was observed to be effectuate. The example was adjust on a tenant $\left(90^{\circ}\right)$ and it is moved along the negative $(-Z)$ to positive $(+Z)$ hub, which is the heading of proliferation of the laser pillar. The exposition of criterion table can be restraint by PC for regularity of every elaboration. To describe transmitted strength through the example was congregate by a photograph locator and it is estimated by the computerized control meter [26].

Figs. 8(a) and (b) portray the closed and open aperture Z-scan curves of EMSHP crystal. The intensity of an optical maser beam (decrease or increase) instantly confide on the material's refractive index and its absorption nature. The sample causes a remnant focusing or defocusing, confide on whether nonlinear refraction is positive or negative [27]. The maximum valley at the focus $(\mathrm{Z}=0)$ is indicative of the two photon absorption (TPA) or contrary saturable absorption (RSA) [28]. The nonlinear absorption was calculated from the OA Z-scrutinize spectrum. However, the CA Z-scrutinize curve gives pre-focal valley and post-focal peak indicates a self-focusing effect and it accomplish a positive sign of nonlinear refractive index $\left(+n^{2}\right)[29]$.

The Z-scrutinize data were resolved accordingly to the antecedently describe method [30]. The variation between the peak and valley transmission $(\Delta \mathrm{Tp}-\mathrm{v})$ is written in expression of the on spindle phase distribute at the focus as,

$$
\Delta \mathrm{T}_{\mathrm{p}-\mathrm{v}}=0.406(1-\mathrm{S})^{0.25}|\Delta \Phi|
$$


The amplitude of this Z-scan can be simply narrated to the nonlinear phase distribute $(\Delta \Phi)$ in the material at the beam waist. $S$ is the linear transmittance aperture and it was adapted using the relation [31].

$$
\mathrm{S}=1-\exp \left(-2 \mathrm{r}^{2} \mathrm{a} / \omega^{2} \mathrm{a}\right)
$$

where $r_{a}$ is the aperture and $\omega_{a}$ is the beam radius at the aperture. The nonlinear refractive index is given by:

$$
\mathrm{n}_{2}=\frac{\Delta \Phi}{K I_{0} L_{\text {eff }}}
$$

where $\mathrm{k}=\frac{2 \pi}{\lambda}$ ( $\lambda$ is the laser wavelength) $\mathrm{I}_{0}$ is the intensity of the laser beam at the focus $(\mathrm{Z}=0), L_{e f f}=[1-\exp (\alpha \mathrm{L})] / \alpha$ is the effective thickness of the sample, $\alpha$ is the linear absorption and $L$ is the thickness of the sample.

From the open aperture Z-scan data, the nonlinear absorption coefficient is estimated as:

$$
\beta=\frac{2 \sqrt{2 \Delta T}}{I_{0} L_{e f f}}
$$

where $\Delta \mathrm{T}$ is the one valley value at the open aperture Z-scan curve. The value of $\beta$ will be negative for saturable absorption and positive for two photon absorption. The real and imaginary parts of the third order nonlinear optical susceptibility $\left(\chi^{(3)}\right)$ are defined as

$$
\begin{aligned}
& \operatorname{Re} \chi^{(3)}(\mathrm{esu})=10^{-4}\left(\varepsilon_{0} c^{2} n_{0}^{2} n_{2}\right) / \pi\left(\mathrm{cm}^{2} / \mathrm{W}\right) \\
& \operatorname{Im} \chi^{(3)}(\mathrm{esu})=10^{-2}\left(\varepsilon_{0} c^{2} n_{0}^{2} \lambda \beta\right) / 4 \pi^{2}(\mathrm{~cm} / \mathrm{W})
\end{aligned}
$$

where $\varepsilon_{0}$ is the vacuum permittivity, $\mathrm{n}_{\mathrm{o}}$ is the linear refractive index of the sample and $\mathrm{c}$ is the velocity of light in vaccum. The nonlinear index of refraction is proportional to the real part of the third order susceptibility $\operatorname{Re}\left(\chi^{(3)}\right)$ and the nonlinear absorption coefficient is proportional to $\mathrm{Im}$ $\left(\chi^{(3)}\right)$. The absolute value of $\left(\chi^{(3)}\right)$ was calculated from:

$$
\left|\chi^{(3)}\right|=\left[\left(\begin{array}{ll}
\mathrm{R} & \text { e }\left(\chi^{(3)}\right)
\end{array}\right)^{2}+\left(\operatorname{Im}\left(\chi^{(3)}\right)\right)^{2}\right]^{1 / 2}
$$

Additionally, the molecular second hyperpolarizability $(\gamma)$ of the crystal is calculated using the expression:

$$
\gamma=\frac{\chi^{(3)}}{N * f}
$$

where $N^{*}$ is the number of molecules per unit volume in $\mathrm{cm}^{3}$. It can be obtained from following

equation:

$$
\mathrm{N}^{*}=\frac{\rho \times N a}{M}
$$

where $\rho$ is the density of material $\left(1.470 \mathrm{mg} / \mathrm{cm}^{3}\right), N A$ is Avogadro's number $\left(6.023 \times 10^{23} \mathrm{~mol}^{-1}\right)$ and $M$ is the molecular weight $(385.28 \mathrm{~g} / \mathrm{mol})$ of the EMSHP single crystal.

According to Lorentz relation

$$
\mathrm{F}=\frac{\mathrm{no} 2+2}{3}
$$

where no is the linear refractive index (1.82) of the material.
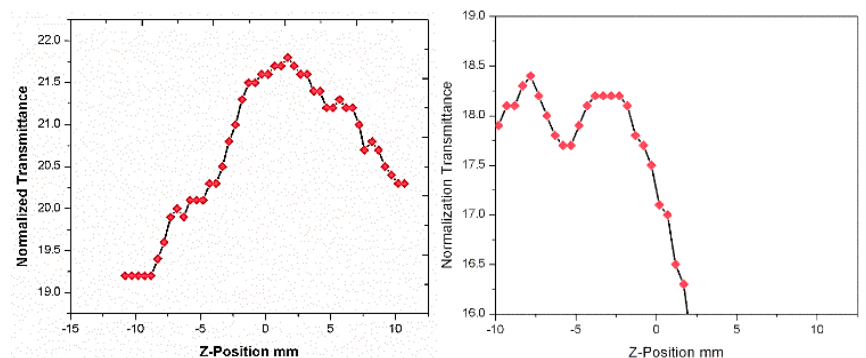

Fig. 8 (a) Open aperture Z-scan curve of curve of EMSHP and (b) Close aperture Zscan curve of curve of EMSHP

The procured open aperture data, the intenseness transmitted by the specimen was moderated as an activity of assertion along the Z-axis. Fig 8(a) shows that experimental open aperture (OA) Z-scrutinize data. From the open aperture Z-scrutinize curve, it can be terminate that as the minimum falsehood near the focus $(\mathrm{Z}=0)$, the nonlinear absorption is https://doi.org/10.30799/jnst.114.18040307 estimate as two photon absorption (TPA) [32]. The nonlinear two photon absorption coefficient $(\beta)$ is found to be $8.94 \times 10^{-4} \mathrm{~m} / \mathrm{W}$. In order to determine the sign of third order susceptibility $\left(\chi^{(3)}\right)$ and to perscrutate the referential contribution from its genuine and imaginary parts, closed aperture (CA).

Z-scrutinize studies were conducted as accomplished from Fig. 8(b) from the Z-scrutinize data the real and imaginary parts of the $\chi^{(3)}$ have been calculated to be $4.116 \times 10^{-9}$ esu and $3.857 \times 10^{-5}$ esu. The value of $\chi^{(3)}$ is found to be larger than the other well-known constitute and it is due to the $\pi$-electron tarnish movement from the donor to acceptor which makes the molecule highly polarized [33]. Thus the EMSHP crystal accomplish the self-defocusing accomplishment might serve as an exquisite licentiate for recurrence in preservation of optical sensors. The Z-scrutinize data for EMSHP single crystal is given Table 4.

Table 4 Z-scan data for EMSHP crystal

\begin{tabular}{ll}
\hline Parameter & Value \\
\hline Laser beam wavelength $(\lambda)$ & $632.8 \mathrm{~nm}$ \\
Lens focal length $(\mathrm{F})$ & $30 \mathrm{~mm}$ \\
Optical path length & $85 \mathrm{~cm}$ \\
Beam radius of the aperture $(w a)$ & $3.3 \mathrm{~mm}$ \\
Aperture radius $(\mathrm{ra})$ & $2 \mathrm{~mm}$ \\
Sample thickness $(L)$ & $1 \mathrm{~mm}$ \\
Incident intensity of the focus $(\mathrm{Z}=0) \mathrm{I}_{0}$ & $4.25 \times 10^{6} \mathrm{Mw} / \mathrm{cm}^{2}$ \\
Effective thickness of the sample $\left(\mathrm{L}_{\mathrm{eff}}\right)$ & $0.989 \times 10^{-3} \mathrm{~m}$ \\
Linear absorption co-efficient $(\alpha)$ & 0.109 \\
Non-linear refractive index ( $\left.\mathrm{n}_{2}\right)$ & $4.938 \times 10^{-11} \mathrm{~m}^{2} / \mathrm{W}$ \\
Non-linear absorption co-efficient $(\beta)$ & $8.94 \times 10^{-4} \mathrm{~m} / \mathrm{W}$ \\
Real part of the third - order susceptibility & $4.116 \times 10^{-9} \mathrm{esu}$ \\
(Re $\left.\chi^{(3)}\right)$ & \\
Imaginary part of the third - order susceptibility & $3.857 \times 10^{-5} \mathrm{esu}$ \\
(Im $\left.\chi^{(3)}\right)$ & \\
Third-order nonlinear optical susceptibility $\left(\chi^{(3)}\right)$ & $3.989 \times 10^{-5} \mathrm{esu}$ \\
Second-order molecular hyperpolarizability $(\gamma)$ & $2.202 \times 10^{-24} \mathrm{esu}$ \\
Number of molecule per unit volume in $\mathrm{cm}^{3}\left(N^{*}\right)$ & $2.430 \times 10^{18} \mathrm{~cm}^{3}$ \\
\hline
\end{tabular}

\section{Conclusion}

The growth of a novel single crystal EMSHP was achieved by slow evaporation method. The present study demonstrated the enhancement in the size of the crystal achieved through proper choice of solvent and growth conditions. The cell parameters of the grown crystals is determined using single crystal X-ray diffraction analysis. The UV spectrum of EMSHP single crystal shows two prominent peaks $377 \mathrm{~nm}$ corresponding to $\pi-\pi^{*}$ transition $227 \mathrm{~nm}$ to $n-\pi^{*}$ transition. The photo luminescence spectra with strong peak at $(498 \mathrm{~nm})$ indicates the blue to green emission. The two photon absorption coefficient and third order optical nonlinearity of the organic EMSHP crystal were investigated using Z-Scan technique. The third order susceptibility of EMSHP is found to be $3.989 \times 10^{-5}$ esu. The attractive nonlinear optical properties proves that EMSHP is a suitable candidate for application in laser industry and electrooptic devices and terahertz wave applications.

\section{References}

[1] Y. Shi, C. Zhang, H. Zhang J.H. Bechtel, L.R. Dalton, B. Robinson, W. Steier, Low (Sub-1-volt) halfwave voltage polymeric electro-optic modulators achieved by controlling chromophore shape, Sci. 288 (2000) 119-122.

[2] A.F. Benner, M. Ignatowski, J.A. Kash, D.M. Kuchta, M.B. Ritter, Exploitation of optical interconnects in future server architectures, IBM J. Res. Dev. 49 (2005) 755-775.

[3] A. Schneider, M. Neis, M. Stillhart, B. Ruiz, R. Khan, P. Gunter, Generation of terahertz pulses through optical rectification in organic DAST crystals: theory and experiment, J. Opt. Soc. Am. B 23 (2006) 1822-1835.

[4] Ch. Bosshard, R. Spreiter, L. Degiorgi, P. Gunter, Infrared and Raman spectroscopy of the organic crystal DAST: Polarization dependence and contribution of molecular vibrations to the linear electro-optic effect, Phys. Rev. B 66 (2002) 205107-205109.

[5] D.S. Chemla, J. Zyss, Nonlinear optical properties of organic molecules and crystals, Academic Press, New York, 1987.

[6] Ch. Bosshard, K. Sutter, Ph. Pretre, J. Hulliger, M. Florsheimer, P. Kaatz, P. Gunter, Organic nonlinear optical materials, Gordon and Breach Science Publishers, SA, Switzerland, 1995

[7] J.Y. Lee, K.S. Kim, B.J. Mhin, Intramolecular charge transfer of $\pi$-conjugated push-pull systems in terms of polarizability and electronegativity, J. Chem. Phys. 115(20) (2001) 9484-9489.

[8] P.N. Prasad, D.J. Williams, Introduction to nonlinear optical effects in organic molecules and polymers, John Wiley \& Sons, New York, 1991.

[9] J.Y. Lee, K.S. Kim, Relationship between spectral intensities and nonlinear optical properties, J. Chem. Phys. 107(17) (1997) 6515-6520. 
[10] P. Gangopadhyay, S. Venugopal Rao, D. Narayana Rao, T.P. Radhakrishnan, NAlkyl-p-nitroanilines: impact of alkyl chain length on crystal structures and optical SHG, J. Mater. Chem. 9 (1999) 1699-1705.

[11] K. Jug, S. Chiodo, F. Janetzko, Polarizabilities and first hyperpolarizabilities of stilbene analogues, Chem. Phys. 287 (2003) 161-168.

[12] P. Calaminici, K. Jug, A.M. Koster, C. Arbez-Gindre, C.G. Screttas, Mechanism for large first hyperpolarizabilities of phosphonic acid stilbene derivatives, J. Comp. Chem. 23 (2002) 291-297.

[13] F. Meyers, S.R. Marder, J.W. Perry, In: Chemistry of advanced materials (Eds: L.V. Interrante, M.J. Hampden-Smith), Wiley-VCH, New York, 1998, p.244.

[14] S.R. Marder, J.W. Perry, W.P. Schaefer, Synthesis of organic salts with large second-order optical nonlinearities, Sci. 245 (1989) 626-628.

[15] U. Meier, M. Bosch, Ch. Bosshard, F. Pan, P. Gunter, Parametric interactions in the organic salt 4-N,N-dimethylamino-4'-N'-methyl-stilbazolium tosylate at telecommunication wavelengths, J. Appl. Phys. 83 (1998) 3486-3489.

[16] F. Pan, K. McCallion, M. Chiappetta, Waveguide fabrication and high-speed inline intensity modulation in $4-\mathrm{N}, \mathrm{N}-4^{\prime}$-dimethylamino- $4^{\prime}-\mathrm{N}^{\prime}$-methylstilbazolium tosylate, Appl. Phys. Lett. 74(4) (1999) 492-494.

[17] G. Zerbi, M. Veronelli, S. Martina, A.D. Schluter, G. Wegner, Delocalization length and structure of oligopyrroles and of polypyrrole from their vibrational spectra, J. Chem. Phys. 100(2) (1994) 978-984.

[18] C. Castiglioni, J.T. Lopez Navarrete, G. Zerbi, M. Gussoni, A simple interpretation of the vibrational spectra of undoped, doped and photoexcited polyacetylene amplitude mode theory in the GF formalism, Solid State Commun. 65(6) (1988) 625-630.

[19] R.D.A. Hudson, A.R. Manning, J.F. Gallagher, M.H. Garcia, Synthesis, structure and nonlinear optical properties of some chiral chromophores derived from Lproline, Tetrahedron Lett. 43 (2002) 8375-8378.

[20] M.D. Aggarwal, J. Choi, W.S. Wang, K. Bhat, R.B. Lal, A.D. Shield, et al., Solution growth of a novel nonlinearoptical material: L-Histidine tetrafluoroborate, J. Cryst. Growth 204 (1999) 179-182.

[21] D. Sajan, J. Binoy, B. Pradeep, K. Venkata Krishna, V.B. Kartha, I. Hubert Joe, V.S. Jayakumar, NIR-FT Raman and infrared spectra and ab initio computations of glycinium oxalate, Spectrochim. Acta, Part A 60 (2004) 173-180.
[22] F. Pan, G. Knopfle, Ch. Bosshard, F. Follonier, R. Spreiter, M.S. Wong, P. Gunter, Electrooptic properties of the organic salt $4 \mathrm{~N}, \mathrm{Ndim}$ ethylamino $4^{\prime} \mathrm{N}^{\prime}$ methyl stilbazolium tosylate, Appl. Phys. Lett. 69 (1996) 13-15.

[23] C.H. Choi, M. Kertesz, Conformational Information from vibrational spectra of styrene, trans-stilbene, and cis-stilbene, Jour. Phys. Chem. A 101 (1997) 38233831

[24] N. Ashour, S.A. EI-Kadry, Mahmoud, Electrical and optical properties of Cds films thermally deposited by a modified source, Thin Solid Films 269 (1995) 117-120.

[25] J.W. Wu, J.R. Heflin, R.A. Norwood, K.Y. Wong, O. Zamani-Khamiri, A.F. Garito, et al., Nonlinear-optical processes in lower-dimensional conjugated structures, J. Opt. Soc. Am B 6(4) (1989) 707-720.

[26] P. Karuppasamy, V. Sivasubramani, M. Senthil Pandian, P. Ramasamy, Growth and characterization of semi-organic third order nonlinear optical (NLO) potassium 3,5-dinitrobenzoate (KDNB) single crystals, RSC Adv. 6 (2016) 109105-109123.

[27] M. Sheik-Bahae, A.A. Said, T.H. Wei, D.J. Hagan, E.W. Van Stryland, Sensitive measurement of optical nonlinearities using a single beam, IEEE J. Quant. Electron. 26 (1990) 760-769.

[28] P. Karuppasamy, M.S. Pandian, P. Ramasamy, Crystal growth and characterization of third order nonlinear optical piperazinium bis(4hydroxybenzenesulphonate) (P4HBS) single crystal, Jour. Cryst. Growth 473 (2017) 39-54.

[29] M. Sheik-Bahae, A.A. Said, E.W. Van Stryland, High-sensitivity, single-beam measurements, Opt. Lett. 14 (1989) 955-957.

[30] A.A. Said, T. Xia, D.J. Hagan, E.W. Van Stryland, M. Sheik-Bahae, Nonlinear absorption and refraction in $\mathrm{CuCl}$ at $532 \mathrm{~nm}$, J. Opt. Soc. Am. B Opt. Phys. 14 (1997) 824-828.

[31] H. Li, F. Zhou, X. Zhang. W. Ji, Bound electronic Kerr effect and self-focusing induced damage in second-harmonic-generation crystals, Opt. Commun. 144 (1997) 75-81.

[32] S. Saltiel, S. Tanev, A.D. Boardman, High-order nonlinear phase shift caused by cascaded third-order processes, Opt. Lett. 22 (1997) 148-150.

[33] T.C. Sabari Girisun, S. Dhanuskodi, Linear and nonlinear optical properties of tristhiourea zinc sulphate single crystals, Cryst. Res. Technol. 44 (2009) 1297 1302. 